\title{
Eco-friendly and Safe Role of Juniperus procera in Controlling of Fungal Growth and Secondary Metabolites
}

\author{
Abdel Ghany TM* \\ Botany and Microbiology Department, Faculty of Science, AL-Azhar University, Cairo, Egypt
}

*Corresponding author: Dr. Tarek Mohamed Abdel Ghany, Botany and Microbiology Department, Faculty of Science, AL-Azhar University, Cairo, Egypt, Tel: 00201015386248; E-mail: tabdelghany@yahoo.com

Rec date: April 21, 2014 Acc date: August 26, 2014 Pub date: August 28, 2014

Copyright: () 2014 Ghany TM. This is an open-access article distributed under the terms of the Creative Commons Attribution License, which permits unrestricted use distribution, and reproduction in any medium, provided the original author and source are credited.

\begin{abstract}
Radial growth Aspergillus flavus and Fusarium oxysporum was determined on medium amended with Juniperus procera methanolic extract. The radial growth of A. flavus and F. oxysporum was significantly reduced at 150 and $200 \mathrm{mg}$. The precentage of reduction was $16.55 \%, 48.54 \%$ and $48.64 \%, 59.86 \%$ for A. flavus and $\mathrm{F}$. oxysporum, respectively. However, addition of $J$. procera extract to Carbomar significantly reduced radial growth compared with using Carbomar alone. On the other hand, with addition of the $J$. procera extract, the productivity percentage of aflatoxins B2, aflatoxins B1, sterigmatocystin, cyclopiazonic acid and fusaric acid was reduced by $100,67.44,96.28$, 60.33 and $8.36 \%$, respectively as a result of applied $J$. procera extract. Moreover, the extract of $J$. procera significantly reduced the $\mathrm{F}$. oxysporum colony-forming units (cfu) in the cultivated soil with Raphanus sativus at 5 days. F. oxysporum populations at 100 and $200 \mathrm{mg}$ of $\mathrm{J}$. procera extract were $25.33 \times 103$ and $21.33 \times 103 \mathrm{cfu} \mathrm{g}-1$, respectively. However, when added with Carbomar, extract of $J$. procera strongly reduced $F$. oxysporum populations $\left(9.33 \times 10^{3}\right.$ cfu $\left.\mathrm{g}-1\right)$. In addition, the $J$. procera extract reduced the mean disease rating of wilt disease of $R$. sativus caused by F. oxysporum. Less content of chlorophyll $a$ and b $(3.56$ and $1.65 \mathrm{mg} / \mathrm{g}$ fresh weight, respectively at $\mathrm{P}<0.01$ ) was detected in infected $R$. sativus than treated with $J$. procera extract or Carbomar.
\end{abstract}

Keywords: Eco-friendly role; Fungal growth; Juniperus procera; Secondary metabolites

\section{Introduction}

Public pressure to minimize the use of chemical fungicides in agriculture has increased in the recent years [1]. The extensive use of chemical fungicides in plant protection against fungal disease generates long-term residues in food and in the environment $[2,3]$. Pesticide residues and development of resistant strains of fungi from the continuous application of pestcides are the major constraints to their use [4]. Various studies have confirmed the efficacy of plant extracts in the control of fungal diseases [5-12], with the view to countering obvious pollution problems in the environment and avoiding the toxic effects of synthetic chemicals on non-target organisms. Plant derived compounds possess a high potential for pest management since most of them are not phytotoxic, easily biodegradable and sometimes stimulatory to the host metabolism $[13,14]$, and thus may have inhibitory effects on fungi and other microorganisms $[15,16]$ as well as mycotoxin production [17-19]. Juniperus is one of the major genera of Cupressaceae family. It is estimated that 70 species of Juniperus are distributed throughout the world [20]. Juniperus species have been extensively investigated as a source of natural products with potential antibacterial, antifungal and insecticidal activities [21-25]. J. procera is used locally to treat tuberculosis and jaundice [26], intestinal worms and eye infections (Klaus and Adala), its wood is resistant to termite and rot [27]. Pankaj et al. [28] investigated the different fractions of Juniperus leaves and bark, it inhibit the growth of aflatoxigenic Aspergillus flavus and A. niger. Extracts from the aerial parts of J. lucayana were assayed against phytopathogenic fungus Botrytis cinerea. The hexane extract showed to have a higher antifungal activity than ethanolic extract [29]. Pirzada et al. [30] studied the effect of ethanol, methanol, ethylacetate, chloroform and aqueous extracts of Juniperus against the human pathogenic fungi (Aspergillus niger and $A$. flavus). Fungal contamination is undesirable because of the potential for mycotoxin production. Aspergillus genera are the most important toxigenic fungi [31]. Aflatoxins are a potent toxic produced as secondary metabolites by the fungus $A$. flavus [32]. Furthermore several other extrolites are produced by $A$. flavus, including cyclopiazonic acid, aspergillic acid and $\beta$-nitropropionic acid [33]. Antifungal agents extracted from plants could be exploited in controlling the growth of fungi consequently inhibiting aflatoxin formation [34].

Plant essential oils and their components have been known to exhibit biological activities such as antifungal [35]. Juniper essential oil was evaluated by Pepeljnjak [36] for the antimicrobial activity against sixteen bacterial species, seven yeast-like fungi, three yeast and four dermatophyte strains. Juniper essential oil showed bactericidal activities as well as a strong fungicidal activity against yeasts, yeast-like fungi and dermatophytes. Recently, Mariana and Camelia, [37] reported that Juniper oil has inhibition action against Aspergillus niger, Fusarium oxysporum, Monascus purpureus and Penicillium hirsutum. Glisic et al. [38] stated that the oil of J. communis with a high content of a-pinene, and mixture of $\alpha$-pinene and sabinene showed the highest antimicrobial activity, especially against fungi. The purpose of this study was to determine whether the natural control of $A$. flavus and $F$. oxysporum and their mycotoxins could be achieved by applying $J$. procera extract and to compare them with the effect of chemical fungicide Carbomar. 


\section{Materials and Methods}

\section{Plant material and preparation of extract}

The leaves of Juniperus procera were collected in January 2012 from Fifa Mountains, Jazan, Kingdom of Saudi Arabia (KSA). The plant sample was kindly identified by Dr. Abduo Marie, Associate Professor of Plant Ecology, Biology department, Faculty of science, Jazan University, KSA according to Migahid, [39] and Chaudhary, [40]. Freash leaves $(500 \mathrm{~g})$ of juniper (J. procera) were air-dried at room temperature under shade, and ground into powder using an electric grinder. Then extracted with methanol in a Soxhlet apparatus. The solvent was removed using rotary evaporator under reduced pressure at temperature below $50^{\circ} \mathrm{C}$. The resulting crude extracts were stored at $4^{\circ} \mathrm{C}$ in dark until used.

Chemical fungicide: Carbomar (Methyl Benzimacold-2ylcarbamate) was used as chemical fungicide. It was prepared in Gyangsoetrnal, China.

Fungal strains: Raphanus sativus seedlings showing symptoms of wilt were collected from farm in Minufiya governorate, Egypt, and transferred in ployethylene bags to the laboratory. The fungal pathogen was isolated from root tissues on potato dextrose agar (PDA) medium according to the growth requirements of the isolate at $25^{\circ} \mathrm{C}$ for 5 days. The obtained Fusarium; F. oxysporum, was purified and identified using PDA media according to the morphological characteristics of the mycelia and spores as described by Domsch and Gams [41], Domsch et al. [42] and John and Brett as F. oxysporum. Aspergillus flavus strain was isolated from spoiled grains (Zea mayse L.) and identified according to Raper and Fennell [43].

\section{Investigation of antimycotic activity}

Inhibitory effect of $J$. procera extract on mycelial radial growth of test fungi was performed by placing $5 \mathrm{~mm}$ mycelia agar disks, cuts from the periphery of 5-day-old culture of the target fungi, in the centre of Petri dishes $(9.0 \mathrm{~cm}$ diameter $)$ containing PDA medium supplemented with 100,150 and $200 \mathrm{mg} J$. procera extract, $10 \mathrm{mg}$ fungicide (Carbomar) and mixture of $200 \mathrm{mg} J$. procera extract with 10 $\mathrm{mg}$ Carbomar. Colony radius was measured after incubation period (8 days) at $27^{\circ} \mathrm{C}$. The control sets were prepared subsequently using sterile distilled water instead of $J$. procera extract. The percent inhibition of the radial growth of the target fungi was calculated according to the following formula. Percent inhibition=(DC-DT)/ $\mathrm{DC} \times 100$, where DC is the colony diameter of the control sets and DT is the colony diameter of the treated sets. Diagnostic chariteria of $F$. oxysporum only were recorded at each treatment by using software for image analysis at Faculty of Science, Jazan university, Saudi Arabia.

\section{Secondary metabolites analysis}

After 10 days of incubation period, the growth medium (potato dextrose broth medium containing $200 \mathrm{mg}$ of $J$. procera) of $A$. flavus and $F$. oxysporum containing extracellular metabolites was extracted twice with Chloroform/methanol $(2: 1 \mathrm{v} / \mathrm{v})$, then concentrated and separated using High-Performance Thin-Layer Chromatography (HPTLC) techniques. Twenty microliters of the samples, with or without treatment, were applied to HPTLC plates $(10 \mathrm{~cm} \times 10 \mathrm{~cm}, 0.2$ mm silica gel Merck 60 F 254 precoated plate; Merck Darmstadt, Germany) using CAMMAG LINOMAT 5 application system. The TLC plates were eluted for the detection of extracellular metabolites in toluene/ethyl-acetate/90\% formic acid 5:4:1 (TEF). Once the runs had finished, the plates were observed under visible and ultraviolet at 254 \& $365 \mathrm{~nm}$ illumination. Griseofulvin dissolved in chloroform/ methanol 2:1 was used as standard in all cases and relative retention factor value ( $\mathrm{Rf}$ value) to griseofulvin were calculated as Rfg. To identify the metabolites the absolute $\mathrm{Rf}$ and the relative $\mathrm{Rf}$ to griseofulvin (Rfg) were measured. Secondary metabolites were identified by descriptions in literature and comparison with the available standard was made [44-47]. Retention factor value ( $\mathrm{Rf}$ value): The distance that the spot of a particular compound moved up on the TLC plate relative to the distance moved by the solvent front is called the retention factor or $\mathrm{Rf}$ value. The $\mathrm{Rf}$ values of individual secondary metabolites were calculated by following, $\mathrm{Rf}=$ Distance traveled by the compound/Distance travelled by the solvent. Quantification of secondary metabolites were done by comparing the $\mathrm{Rf}$ values and area $\%$ of secondary metabolite calculated using CAMMAG TLC scanner at Regional Center for Mycology and Biotechnology (RCMB), Al-Azhar University Cairo, Egypt. The percentage of Metabolite production inhibition was calculated using the following formula: ( 1 - Area of test sample/Area control) $\times 100 \%$.

Analysis of fungal fatty acids: Mycelium (5 g fresh weight) of $A$. flavus and F. oxysporum (cultivated on potato dextrose broth medium containing $200 \mathrm{mg}$ of $J$. procera) was grinded in $10 \mathrm{ml}$ Chloroform: Methanol $(2: 1 \mathrm{v} / \mathrm{v})$, then filtered and concentrated into $1 \mathrm{ml}$. The concentrated extract was placed in Gas Chromatography (GC) autosampler vials until they were analyzed using Shimadzu GCMS-QP 5050 A. software class 5000. Searched library: Wiley229 LIB. Column: DB1, $30 \mathrm{~m}, 0.53 \mathrm{~mm}$ ID; $1.5 \mu \mathrm{m}$ film. Carrier gas: Helium (flow rate 1 $\mathrm{ml} / \mathrm{min}$.). Ionization mode: $\mathrm{El}(70 \mathrm{ev})$. Temperature program: $70^{\circ} \mathrm{C}$ (static for $2 \mathrm{~min}$ ) then gradually increasing (at a rate of $2^{\circ} \mathrm{C} / \mathrm{min}$ ) up to $220^{\circ} \mathrm{C}$ (static for $5 \mathrm{~min}$ ). Detector temperature was set at $250^{\circ} \mathrm{C}$ and injector temperature at $250^{\circ} \mathrm{C}$. The chromatographs were compared and individual peaks were identified by comparing mass spectra to the library references, at RCMB.

Pot experiment: Pots containing 750 g of autoclaved agricultural soil and cultivated with 15 seeds of radish (Raphanus sativus) surfacedisinfected in $0.5 \%$ sodium hypochloride solution for $3 \mathrm{~min}$, rinsed three times in sterile-distilled water prior to sowing, in an air conditioned glasshouse at $25-28^{\circ} \mathrm{C}$, the soil was inoculated with $10 \mathrm{~mm}$ mycelia agar disk of $F$. oxysporum mycelia with their spores $(1 \times 104 / \mathrm{ml})$ and the soil was treated with various concentration of 100 to $200 \mathrm{mg}$ J. procera extract, $10 \mathrm{mg}$ Carbomar and mixture of $200 \mathrm{mg}$ J. procera extract with $10 \mathrm{mg}$ Carbomar. Control soil was treated separately with $F$. oxysporum and $J$. procera extract. After 10 to 20 days the growing and wilting seedlings were observed and quantitative determination of chlorophyll was estimated in the rest of seedlings.

Quantitative determination of chlorophyll content: Chlorophyll a and $\mathrm{b}$ were extracted from the leaves of Raphanus sativus and estimated by the method of Vernon and Seely [48] using the following equations:

Chlorophyll a $(\mathrm{mg}) /(\mathrm{g})$ fresh weight=11.63 (A665) - 2.39 (A649).

Chlorophyll b (mg)/(g) fresh weight=2.11 (A649) - 5.18 (A665).

Where (A), denotes the reading of the optical density.

Colony forming units of Fusarium oxysporum:After 1, 5, 10 and 15 days of $J$. procera extract and chemical fungicide (Carbomar) application in pot experiment with agricultural soil, cultivated with $R$. sativus, the total numbers of inoculated $F$. oxysporum was counted. 
The numbers of colony forming units (CFU) in the selective media were determined by means of the serial dilution technique and the spread plate method. Analyses were performed in three replicates. Viable count of $F$. oxysporum was performed using rose bengalstreptomycin agar containing (per liter): $10 \mathrm{~g}$ glucose; $5 \mathrm{~g}$ peptone; $\mathrm{g}$ $\mathrm{K} 2 \mathrm{HPO} 4 ; 0.5 \mathrm{~g} \mathrm{MgSO} 4 \times 7 \mathrm{H} 2 \mathrm{O} ; 0.033 \mathrm{~g}$ rose bengal; $15 \mathrm{~g}$ agar. The plates were incubated at $28^{\circ} \mathrm{C}$ and colonies were counted after 5 days.

All data were subjected to one-way analysis of variance (ANOVA) using a software package (SPSS ver. 15). The significance among treatments in each time interval was determined using the least significant difference test (LSD, $\mathrm{P}<0.05$ and $\mathrm{P}<0.01)$.

\section{Results and Discussion}

\section{In vitro antimycotic activity}

Growth of A. flavus and F. oxysporum (Table 1 and Figure 1) indicated that both fungal species were sensitive to the $J$. procera extract with the severe inhibition of colony radius compared with the control. There was significant difference $(\mathrm{P}<0.01)$ among colony radius of A. flavus and $\mathrm{F}$. oxysporum at different concentration of $J$. procera extract alone, J. procera extract with carbomar and carbomar alone and control. This confirms the antifungal activities exerted by juniper extracts against fungal mycelium [21,23,25]. Growth of A. flavus and $\mathrm{F}$. oxysporum was decreased with increasing concentrations of $J$. procera extract (Figure 1B-D). On the other hand the antifungal activity of Carbomar was more pronounced (Figure 1E) against A. flavus and F. oxysporum. Furthermore, J. procera extract combined with Carbomar resulted in the best control of fungal species compared with using each of them alone, where the growth inhibition \% was 82.1 and $88.42 \%$ for A. flavus and F. oxysporum and respectively (Table 1), similar findings were reported by Pirzada et al. [30]. Pankaj et al. [28] reported that the different fractions of Juniperus leaves and bark inhibit the growth of aflatoxigenic A. flavus and A. niger at concentrations ranged from 1000 to $4000 \mathrm{ppm}$ of methanolic extract. The antifungal properties of $J$. procera may due to the presence of sandaracopimaric acid [29,49], diterpenes totarol, ferruginol, $7 \beta$ hydroxyabieta-8, 13-dien-11,12-dione, and 4-epiabetol [50].

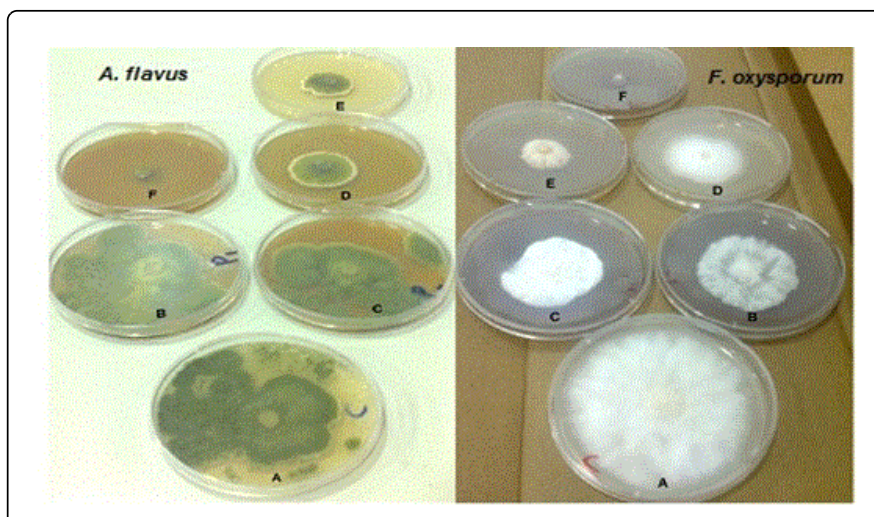

Figure 1: Growth of A. flavus and F.oxysporum on medium without treatment as control (A), with $100 \mathrm{mg}$ of $J$. procera extract (B), 150 $\mathrm{mg}$ of $J$. procera extract (C), $200 \mathrm{mg}$ of $J$. procera extract (D), $10 \mathrm{mg}$ fungicide (E), $200 \mathrm{mg}$ of $J$. procera extract and $10 \mathrm{mg}$ chemical fungicide $(\mathrm{F})$

\begin{tabular}{|l|l|l|l|l|}
\hline \multirow{2}{*}{ Concentration of J. procera extract $(\mathrm{mg})$} & \multicolumn{4}{l|}{ Growth and inhibition percentage (\%) (mean \pm SE) } \\
\cline { 2 - 5 } & \multicolumn{2}{|l|}{ A. flavus } & \multicolumn{2}{l|}{ F. oxysporum } \\
\cline { 2 - 5 } & Colony radius $(\mathrm{mm})$ & Inhibition $(\%)$ & Colony radius (mm) & Inhibition (\%) \\
\hline Control & $4.47 \pm 0.15$ & 0.00 & $7.40 \pm 0.10$ & 0.00 \\
\hline 100 & $4.17 \pm 0.15^{* *}$ & 6.71 & $4.30 \pm 0.10^{* *}$ & 41.89 \\
\hline 150 & $3.73 \pm 0.06^{* *}$ & 16.55 & $3.80 \pm 0.10^{* *}$ & 48.64 \\
\hline 200 & $2.30 \pm 0.10^{* *}$ & 48.54 & $2.97 \pm 0.12^{* *}$ & 59.86 \\
\hline Carbomar $(10 \mathrm{mg})$ & $1.83 \pm 0.06^{* *}$ & 62.90 & $1.77 \pm 0.15^{* *}$ & 76.08 \\
\hline Carbomar $(10 \mathrm{mg})+J$. procera extract $(200 \mathrm{mg})$ & $0.80 \pm 0.10^{* *}$ & 82.10 & $0.87 \pm 0.06^{* *}$ & 88.42 \\
\hline
\end{tabular}

Table 1: Growth of A. flavus and F.oxysporum on medium supplemented with different concentrations of J. procera extract and their mixture with chemical fungicide (Carbomar). Value is the mean \pm SD of three replicates. ${ }^{*}$ The mean difference is significant at the 0.01 level.

Extract of $J$. procera demonstrated good inhibitory effect on secondary metabolites production as well as mycotoxins of A. flavus and F. oxysporum (Tables 2 and 3). Production of all detected secondary metabolites (except aspergillic acid) of A. flavus including aflatoxins B1, sterigmatocystin, cyclopiazonic acid and ergosterol were reduced (Production inhibition was 67.44, 96.28, 60.33 and 42.75\% respectively), while production of aflatoxins B2 was completely inhibited with the treatment of J. procera extract (Table 2). Fungitoxic effects indicate that $J$. procera extract block the biosynthesis pathway of aflatoxins B2. On the other hand, $J$. procera extract induced the production of 3-Nitropropionic acid. These results are partially supported by reports indicating that extracts of certain plants were able to inhibit production of aflatoxin, sterigmatocystin and cyclopiazonic acid [17,51].

It was revealed from the results (Table 3 ) that $J$. procera extract inhibit the secondary metabolites production of $\mathrm{F}$. oxysporum, including fusaric acid and ergosterol (production inhibition was $8.36 \%$ and $73.34 \%$ respectively). Many researchers focused on controlling of F. oxysporum mycotoxins $[10,11,52]$. Fusaric acid is probably one of the most widely distributed mycotoxins produced by strains in the genus Fusarium [53]. 
Citation: Abdel Ghany TM (2014) Eco-friendly and Safe Role of Juniperus procera in Controlling of Fungal Growth and Secondary Metabolites. J

Page 4 of 9

\begin{tabular}{|c|c|c|c|c|c|}
\hline \multirow[t]{3}{*}{ Secondary metabolites } & \multicolumn{5}{|c|}{ Secondary metabolites of A. flavus cultivated on medium } \\
\hline & \multicolumn{2}{|c|}{ Without J. procera extract } & \multicolumn{2}{|c|}{ With J. procera extract } & \multirow{2}{*}{$\begin{array}{l}\text { Inhibition (\%) of secondary metabolite production } \\
(\%)\end{array}$} \\
\hline & Area $(A U)$ & Area\% & Area $(A U)$ & Area\% & \\
\hline Aflatoxin B2 & 5692.6 & 11.19 & 0.0 & 0.0 & 100 \\
\hline Aflatoxin B1 & 6494.4 & 12.76 & 2114.5 & 5.38 & 67.44 \\
\hline Sterigmatocystin & 4527.3 & 8.90 & 168.4 & 0.43 & 96.28 \\
\hline Aspergillic acid & 23824.4 & 46.81 & 29622.7 & 75.43 & -ve \\
\hline Cyclopiazonic acid & 4078.5 & 8.01 & 1617.7 & 4.12 & 60.33 \\
\hline Ergosterol & 6276.7 & 12.33 & 3592.8 & 9.15 & 42.75 \\
\hline 3-Nitropropionic acid & 0.0 & 0.0 & 2156.0 & 5.49 & -ve \\
\hline
\end{tabular}

Table 2: Secondary metabolites of A. flavus cultivated on medium supplemented with $J$. procera extract (200 mg/100 ml). -ve, Secondary metabolite production increased.

Data in Table 3 show that $J$. procera extract have no suppressive effect on the productivity of other mycotoxins, where T2-Toxin, dihydrofusarbin, dihydroxyscripenol and butenolide productivity increased as compared with their productivity in case of control (without $J$. procera extract). Overall, the findings suggest that this extract has potential for use as antifungal agent (Figure 1), although it

induce certain mycotoxin production and supress other. According to the explanation of Kiran et al. [54], it appears that there is no a relationship between the growth and mycotoxin production. Natural antifungal agents can be potential exploited in controlling the growth of fungi consequently inhibiting mycotoxin production $[51,55,56]$.

\begin{tabular}{|c|c|c|c|c|c|}
\hline \multirow[t]{3}{*}{ Secondary metabolites } & \multicolumn{5}{|c|}{ Secondary metabolites of F. oxysporum cultivated on medium } \\
\hline & \multicolumn{2}{|c|}{ Without J. procera extract } & \multicolumn{2}{|c|}{ With J. procera extract } & \multirow{3}{*}{\begin{tabular}{|l|}
$\begin{array}{l}\text { Inhibition }(\%) \text { of secondary metabolite } \\
\text { production (\%) }\end{array}$ \\
-ve
\end{tabular}} \\
\hline & Area (AU) & Area\% & Area $(A U)$ & Area\% & \\
\hline Dihydroxyscripenol & 2422.3 & 17.41 & 8797.1 & 19.32 & \\
\hline Fusaric acid & 7808.8 & 48.94 & 7155.6 & 15.72 & 8.36 \\
\hline T2-Toxin & 1428.3 & 10.27 & 2087.7 & 4.59 & -ve \\
\hline Butenolide & 594.7 & 4.27 & 3701.0 & 8.13 & -ve \\
\hline Dihydrofusarbin & 130.4 & 0.94 & 326.3 & 0.72 & -ve \\
\hline Ergosterol & 893.5 & 6.42 & 238.2 & 0.41 & 73.34 \\
\hline Emodin & 1634.5 & 11.75 & 2065.7 & 4.54 & $-v e$ \\
\hline Unknown 1 & 0.00 & 0.00 & 12935.3 & 28.42 & -ve \\
\hline Unknown 2 & 0.00 & 0.00 & 8439.1 & 18.04 & -ve \\
\hline
\end{tabular}

Table 3: Secondary metabolites of F. oxysporum cultivated on medium supplemented with $J$. procera extract (200 mg/100 ml). -ve, Secondary metabolite production increased.

The most fatty acids of A. flavus and F. oxysporum mycelia treated with $J$. procera extract were detected in lower concentration compared to the non-treated (Table 4). Overall results indicated that certain fatty acids including caprylic, tridecanoic and pentadecanoic was completely disappeared in A. flavus cultivated in medium amended with J. procera extract. On the other hand, palmitoleic, heptadecanoic, stearic and arachidic acid were decreased $(0.24,0.35,2.42$ and 0.56 $\mathrm{mg} / \mathrm{g}$ ) sharply in F. oxysporum mycelia treated with J. procera extract compared with their concentration $(2.98,6.41,9.43$ and1.82 mg/g) respectively in non-treated. Although the mode of action of $J$. procera extract is not completely explained, it has been suggested that they act over cytoplasmic membranes, producing changes in their fatty acids. Feng and Zheng [57] reported that the natural compounds from plants interfere in the electron transport, the nutrient absorption, the fatty acid synthesis, the adenosine triphosphatase activity, and other metabolic processes of the cell. 
Citation: Abdel Ghany TM (2014) Eco-friendly and Safe Role of Juniperus procera in Controlling of Fungal Growth and Secondary Metabolites. J

Page 5 of 9

\begin{tabular}{|c|c|c|c|c|c|}
\hline \multicolumn{2}{|l|}{ Fatty Acids } & \multicolumn{4}{|c|}{ Fatty acids concentration (mg/g fresh weight) } \\
\hline & & \multicolumn{2}{|l|}{ A. flavus cultivated } & \multicolumn{2}{|l|}{ F. oxysporum cultivated } \\
\hline & & Without J. procera extract & With J. procera extract & Without J. procera extract & With J. procera extract \\
\hline Caprylic & $\mathrm{C} 8$ & 0.31 & 0.00 & 0.04 & 1.89 \\
\hline Capric & C10 & 0.79 & 0.17 & 0.05 & 0.06 \\
\hline Lauric & C12 & 1.48 & 0.36 & 1.83 & 1.12 \\
\hline Tridecanoic & C13 & 0.63 & 0.00 & 0.20 & 0.47 \\
\hline Myristic & C14 & 1.84 & 1.16 & 1.58 & 1.87 \\
\hline Pentadecanoic & C15 & 0.12 & 0.00 & 0.32 & 0.14 \\
\hline Palmitic & C16 & 25.64 & 33.8 & 28.89 & 27.6 \\
\hline Palmitoleic & C16:1 & 0.66 & 0.21 & 2.98 & 0.24 \\
\hline Heptadecanoic & $\mathrm{C} 17$ & 14.92 & 15.19 & 6.41 & 0.35 \\
\hline Oleic & C18:1 & 26.59 & 12.74 & 29.54 & 49.81 \\
\hline Stearic & C18 & 9.78 & 9.17 & 9.43 & 2.42 \\
\hline Linoleic & C18:2 & 7.46 & 22.06 & 16.61 & 11.36 \\
\hline Arachidic & C20 & 7.31 & 5.51 & 1.82 & 0.56 \\
\hline Behenic & C22 & 3.26 & 0.15 & 0.12 & 0.08 \\
\hline
\end{tabular}

Table 4: Fatty acids content of A. flavus and F. oxysporum cultivated in medium supplemented with J. procera extract (200 mg/100 ml).

Carbomar at concentration $10 \mathrm{mg}$ had clear toxicity to $\mathrm{F}$. oxysporum growth as well as their morphology and sporogenisis (Figure $2 \mathrm{E}$ and $\mathrm{F}$ ), where hyphae were deformed with appearance of large vesicles inside hyphae. J. procera extract had a rather similar effect on the F. oxysporum morphology (Figure 2D) at high concentration $(200 \mathrm{mg})$ but had a slight effect at low concentratin 100 and $150 \mathrm{mg}$ (Figure 2A-C). Synergistic effect between Carbomar and $J$. procera extract was observed on diagnostic charaiteria of $\mathrm{F}$. oxysporum (Figure $2 \mathrm{G}$ and $\mathrm{H}$ ) compared with all treatments and control. Different degrees of antifungal activities represented by deformations in the diagnostic charaiteria of $\mathrm{F}$. oxysporum can probably be explained by the varied concentration of the tested $J$. procera extract. Similar results have been reported, showing less number of conidiospores of F. oxysporum as a result of exposure to 20 $\mu \mathrm{L}$ natural mint extract [37].

\section{In vivo antimycotic activity}

The in vivo experiment demonstrated the J. procera extract showed efficient control of F. oxysporum, where the disease symptoms were suppressed when $J$. procera extract was added in $R$. sativus grown in fungus-infested soil. F. oxysporum suppression was based on observations of symptoms of their disease in the wilting and number of growing seedlings (Figure 3). Furthermore, the severity of symptoms decreased with increasing of $J$. procera extract concentration (Figure 3D and E) compared to the fungus-inoculated without any treatments (Figure 3C). Development of safer anti-fungal agents such as plant extracts to control phytopathogens in agriculture were reported in recent years $[25,58]$.

Carbomar had the highest inhibitory effect on F. oxysporum wilt disease (Figure 3F) compared with using J. procera extract. Weitang et al. [59] indicated that carbendazim were the most effective fungicides in inhibiting mycelial growth of F. oxysporum f. sp. Furthermore, the disease severity of $R$. sativus was reduced after an integrated treatment of Carbomar combined with $J$. procera extract (Figure 3G). Surprisingly Nguefack et al. [60] found that the antifungal activity of chemical fungicide (Carbendazim $100 \mathrm{mg} / \mathrm{ml}+$ chlorothalonil 550 $\mathrm{mg} / \mathrm{ml}$ ) was lower than that of plant extract (Ocimum gratissimum and Callistemon citrinus) against Bipolaris oryzae. On the other hand no negative impact was observed on $R$. sativus grown in non fungusinfested soil amended with $J$. procera extract (Figure 3B). According to Bansal and Gupta [61] many plant extracts have been reported to increase seed germination through decreasing $F$. oxysporum incidence. 
Citation: Abdel Ghany TM (2014) Eco-friendly and Safe Role of Juniperus procera in Controlling of Fungal Growth and Secondary Metabolites. J
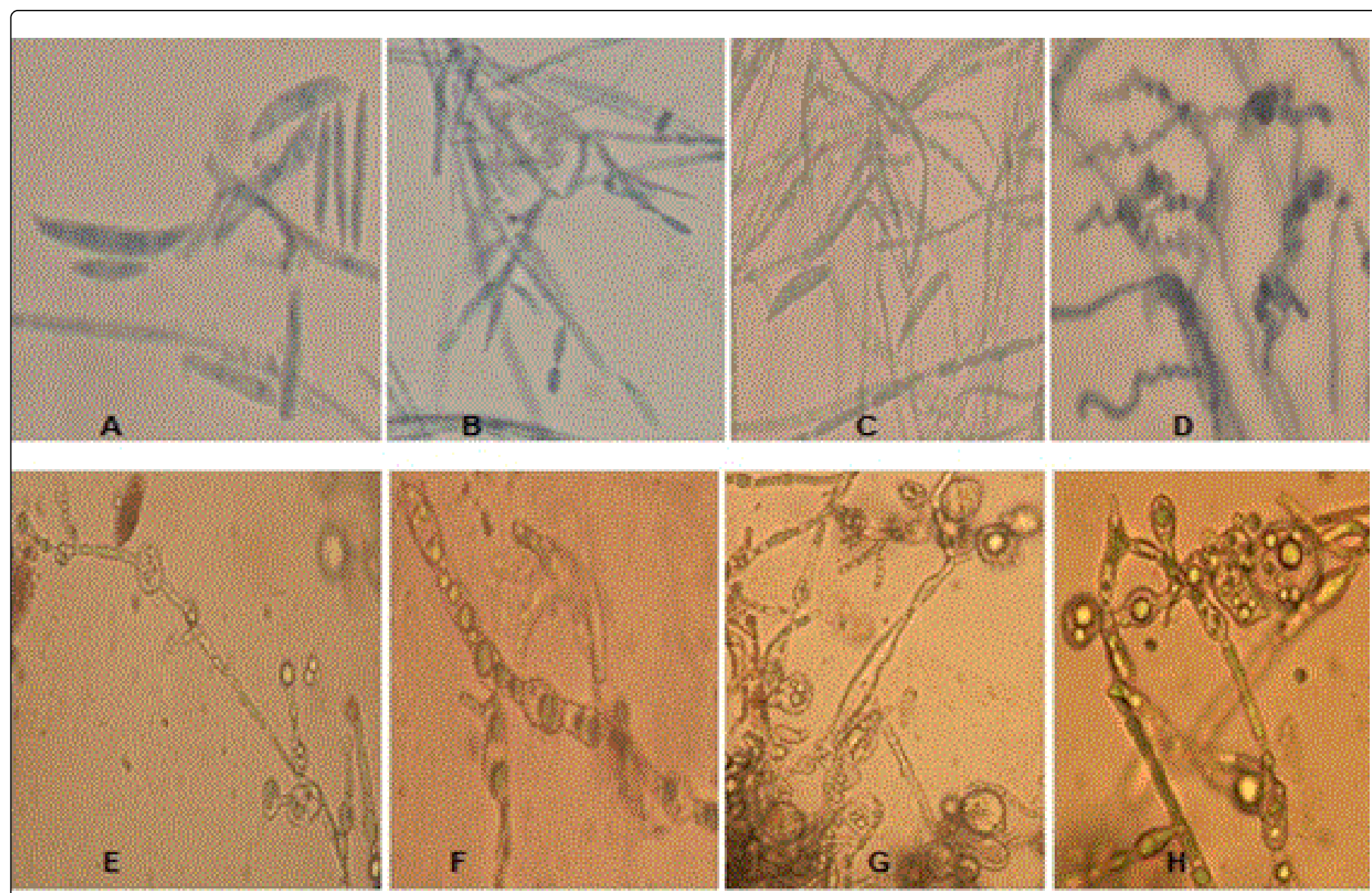

Figure 2: Morphological charaiteria of F. oxysporum in medium without treatment as control (A), $100 \mathrm{mg}$ of $J$. procera extract (B), $150 \mathrm{mg}$ of J. procera extract (C), $200 \mathrm{mg}$ of J. procera extract (D), $10 \mathrm{mg}$ Carbomar (E and F), $200 \mathrm{mg}$ of J. procera extract and $10 \mathrm{mg}$ Carbomar (G and $\mathrm{H})$

Anyway, the results suggest that the $J$. procera extract not only suppress F. oxysporum growth in vitro, but also in vivo. This is not the first study which used the plant extract to control plant pathogens under in vivo conditions. Application of Dittrichia viscosa extract [62], Ocimum basilicum extract [63] neem seed powder [64], J. oxycedrus [65] plant essential oils [66] gave efficient protection against phytopathogens under in vivo conditions. Data presented in Table 5 showed that chlorophyll $\mathrm{a}$ and $\mathrm{b}$ were significantly decreased in $R$. sativus at certain treatment. Minimum content of chlorophyll a and b ( 3.56 and $1.65 \mathrm{mg} / \mathrm{g}$ fresh weight for chlorophyll a and $\mathrm{b}$ respectively at $\mathrm{P}<0.01)$ was observed in $R$. sativus cultivated in soil inoculated with pathogen alone compared with other treatments. Chlorophyll a of $R$. sativus cultivated in soil inoculated with pathogen showed no significant decrease at treatment with $100 \mathrm{mg} J$. procera extract and Carbomar, where it was 4.86 and $4.93 \mathrm{mg} / \mathrm{g}$ fresh weight respectively.

The agricultural soil treated with $J$. procera extract and Carbomar showed significant $(\mathrm{P}<0.01)$ alterations in $\mathrm{F}$. oxysporum population (Table 6). The population of F. oxysporum increased with increasing application time in the fungus-inoculated soil, where the mean of
$\mathrm{CFU} / \mathrm{g}$ was 28.67, 46.33, 56 and 57.33 at $1,5,10$ and 15 days respectively. On the other hand, J. procera extract at 100 and $200 \mathrm{mg}$ suppress F. oxysporum at 5 days of application (CFU was 25.33 and 21.33 respectively). At 10 and 15 days of plant extract application, the population of F. oxysporum increased. This may be due to degradation of active ingredient of $J$. procera. On the other hand the chemical fungicide was more effective than natural extract of $J$. procera. At the same time, the addition of $J$. procera extract $(200 \mathrm{mg})$ to carbomar increased their antifungal activity on CFU of F. oxysporum. Alkhail [67] showed antifungal activity of some plant extracts when tested against fungi viz., F. oxysporum and Botrytis cinerea. Mogle and Maske [68] reported that chemical fungicide Dithane M-45 decreased the mycoflora and enhanced the seeds of cowpea germination percentage [69]. Screening for antimicrobial activity has been the subject of many investigations and plant extracts with very potent antimicrobial activity could be promising agents for in vivo examination. Among such plant extracts is the extract from J. procera and it has been emerged as alternative to replace chemical fungicides. 
Citation: Abdel Ghany TM (2014) Eco-friendly and Safe Role of Juniperus procera in Controlling of Fungal Growth and Secondary Metabolites. J

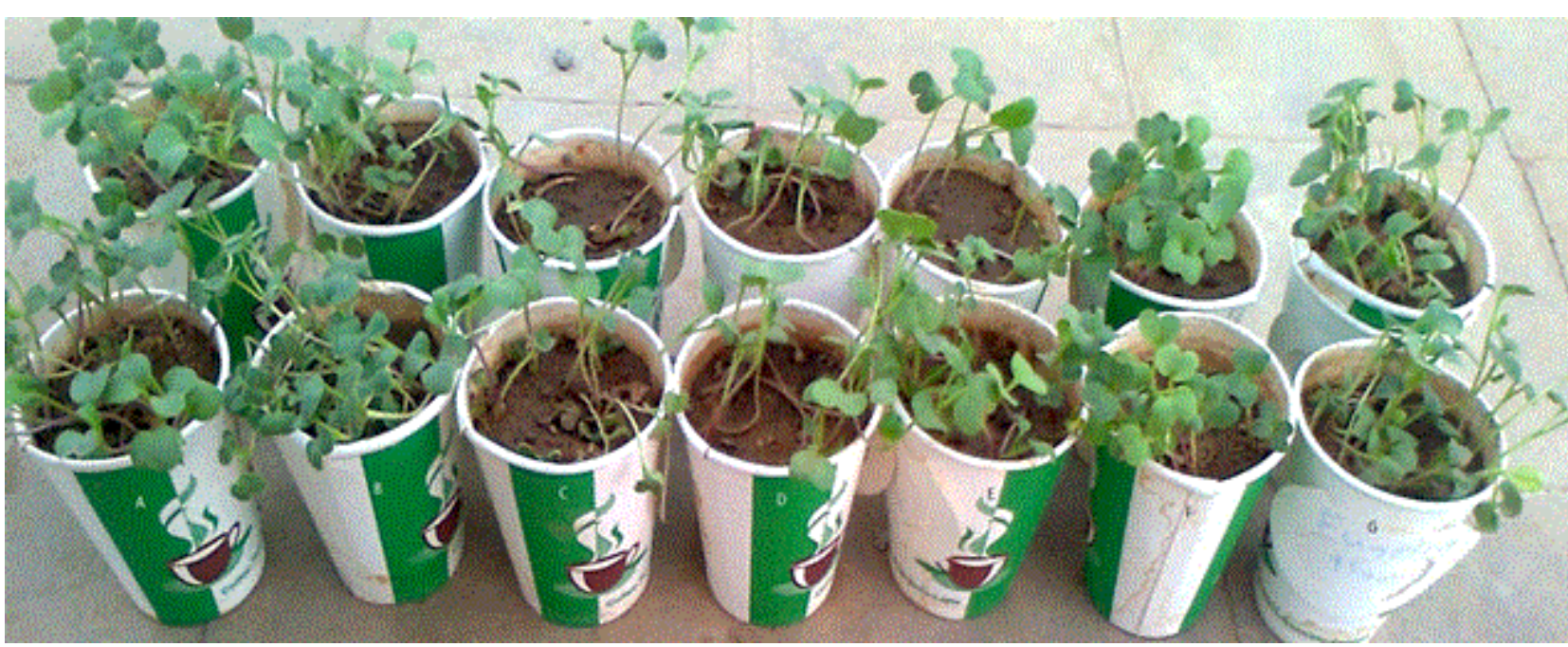

Figure 3: Seedlings growth of $R$. sativus cultivated in control soil without treatment (A), soil treated with $100 \mathrm{mg}$ of $J$. procera extract (B), soil inoculated with F. oxysporum (C), soil inoculated with F. oxysporum and treated with $100 \mathrm{mg}$ of $J$. procera extract (D), soil inoculated with F. oxysporum and treated with $200 \mathrm{mg}$ of $J$. procera extract (E), soil inoculated with F. oxysporum and treated with $10 \mathrm{mg}$ Carbomar (F), soil inoculated with F. oxysporum, treated with $200 \mathrm{mg}$ of J. procera extract and $10 \mathrm{mg}$ Carbomar (G).

\begin{tabular}{|c|c|c|}
\hline \multirow[t]{2}{*}{ Treatments } & \multicolumn{2}{|c|}{ Chlorophyll contents (mg/g fresh weight) } \\
\hline & Chlorophyll "a" & Chlorophyll "b" \\
\hline Control & $4.96 \pm 0.17$ & $2.31 \pm 0.05$ \\
\hline J. procera extract (100 mg) & $4.38 \pm 0.10^{* *}$ & $1.94 \pm 0.06^{*}$ \\
\hline F. oxysporum (FO) & $3.56 \pm 0.03^{\star *}$ & $1.65 \pm 0.10^{\star *}$ \\
\hline J. procera extract (100 mg) and FO & $4.86 \pm 0.06$ & $2.28 \pm 0.06^{\star \star}$ \\
\hline J. procera extract $(200 \mathrm{mg})$ and FO & $3.65 \pm 0.11^{* *}$ & $1.76 \pm 0.06^{\star *}$ \\
\hline J. procera extract $(200 \mathrm{mg})$, Carbomar $(10 \mathrm{mg})$ and FO & $4.23 \pm 0.07^{\star *}$ & $1.93 \pm 0.03^{\star \star}$ \\
\hline Carbomar $(10 \mathrm{mg})$ and FO & $4.93 \pm 0.05$ & $2.30 \pm 0.10^{\star *}$ \\
\hline
\end{tabular}

Table 5: Chlorophyll contents (mg/g fresh weight) of Raphanus sativus seedlings cultivated in soil treated with J. procera extract, F. oxysporum and Carbomar. Control, autoclaved soil and without treatment. ${ }^{*}$ The mean difference is significant at the 0.05 level. ${ }^{* *}$ The mean difference is significant at the 0.01 level.

\begin{tabular}{|c|c|c|c|c|}
\hline \multirow[t]{2}{*}{ Soil treatments } & \multicolumn{4}{|c|}{ Colony forming units (CFU) of F. oxysporum at different days } \\
\hline & 1 & 5 & 10 & 15 \\
\hline Control & $0.00 \pm 0.00$ & $0.00 \pm 0.00$ & $1.33 \pm 0.58$ & $4.67 \pm 1.15$ \\
\hline F. oxysporum (FO) & $28.67 \pm 1.53^{\star *}$ & $46.33 \pm 2.65^{\star *}$ & $56.00 \pm 2.65^{\star *}$ & $57.33 \pm 1.53^{* *}$ \\
\hline J. procera extract (100 mg) and FO & $26.00 \pm 1.00^{* *}$ & $25.33 \pm 1.15^{\star *}$ & $57.67 \pm 1.15^{\star *}$ & $61.33 \pm 1.53^{* *}$ \\
\hline J. procera extract $(200 \mathrm{mg})$ and FO & $23.67 \pm 1.15^{\star \star}$ & $21.33 \pm 1.53^{* *}$ & $36.67 \pm 1.15^{\star *}$ & $42.67 \pm 1.53^{* *}$ \\
\hline J. procera extract $(200 \mathrm{mg})$, Carbomar $(10 \mathrm{mg})$ and FO & $13.33 \pm 0.58^{\star \star}$ & $9.33 \pm 0.58^{\star \star}$ & $8.67 \pm 1.15^{\star *}$ & $17.33 \pm 0.58^{\star \star}$ \\
\hline
\end{tabular}


Table 6: Colony forming units (CFU) of F. oxysporum in soil inoculated with F. oxysporum and treated with J. procera extract and Carbomar at different days of application. Autoclaved soil without treatment was used as control. ${ }^{*}$ The mean difference is significant at the 0.01 level.

\section{Acknowledgement}

Thanks to Regional Center of Mycology and Biotechnology, Al Azhar University, Cairo, Egypt for providing laboratory facilities.

\section{References}

1. Shafique S, Javaid A, Bajwa R (2007) Effect of aqueous leaf extracts of allelopathic trees on germination and seed-borne mycoflora of wheat. Pak. J Bot 39: 2619-2624.

2. Chen Y, Hengkui L, Changjun C, Mingguo Z (2008) Sensitivity of Fusarium graminearum to fungicide JS399-19: In vitro determination of baseline sensitivity and the risk of developing fungicide resistance. Phytoparasitica 36: 326-337.

3. Petit AN, Fontaine F, Clément C, Vaillant-Gaveau N (2008) Photosynthesis limitations of grapevine after treatment with the fungicide fludioxonil. J Agric Food Chem 56: 6761-6767.

4. Baraldi E, Mari M, Chierici E, Pondrelli M, Bertolini P, et al. (2003) Studies on thiabendazole resistance of Penicillium expansum of pears pathogenic fitness and genetic characterization. Plant Pathol 52: 362-370.

5. Stoll G (1988) Natural Protection of Plants in Tropical Zone. Eds Margraf Verlag., CTA, AGRECOL.

6. Amadioha AC, Uchendu PN (2003) Post-harvest of tomato fruit rot caused by Fusarium solani with extracts of Azadirachta, indica Discov Innov 15: 83-86.

7. Obagwu J, Korsten L (2003) Control of citrus green and blue molds with garlic extracts. European J Plant Pathol 109, 221-225.

8. Adandonon A, Aveling TAS, Labuschagne N, Tamo M (2006) Biocontrol agents in combination with Moringa oleifera extract for integrated control of Sclerotium-caused cowpea damping-off and stem rot. Europ J Plant Pathol 115: 409-418.

9. Singh SP, Tanwer BS, Khan M (2010) Antifungal potential of Ashwagandha against some pathogenic fungi. Int J Biopharma 1: 72-74

10. Mamoci E, Cavoski I, Simeone V, Mondelli D, Al-Bitar L, et al. (2011) Chemical composition and in vitro activity of plant extracts from Ferula communis and Dittrichia viscosa against postharvest fungi. Molecules 16: 2609-2625.

11. Rinez A, Daami-Remadi M, Omezzine F, Ladhari A, Rinez L, et al. (2012) Assessment of the antifungal activity of Nicotiana glauca Graham aqueous and organic extracts against some pathogenic and antagonistic fungi. African J Microbiology Rese 6: 4655-4661.

12. Rauf S, Javaid A (2013) Antifungal activity of different extracts of Chenopodium album against Fusarium oxysporum f. sp. cepae the cause of onion basal rot. Interna J Agriculture and Biol 15: 367-371.

13. Mishra AK, Dubey NK (1994) Evaluation of some essential oils for their toxicity against fungi causing deterioration of stored food commodities. Appl Environ Microbiol 60: 1101-1105.

14. Javaid A, Shoaib A (2012) Chapter 12. Allelopathy for the Management of Phytopathogens. In: Allelopathy: Current Trends and Future Applications. Cheema, Z.A., Farooq M., Wahid, A. (Eds.). Springer Publishers, 299-319.

15. Odebode AC, Madachi SJM, Joseph CC, Irungu BN(2004) Antibacterial activities of constituents from Isolona cualifora Verdc and Cleistochlamys krikii Benth(Oliv) (Annonaceae). J Agricultural Sci 49: 109-16.

16. Afifi HAM (2012) Comparative Efficacy of Some Plant Extracts against Fungal Deterioration of Stucco Ornaments in the Mihrab of Mostafa Pasha Ribate, Cairo, Egypt. Am J Biochem Mol Biol 2: 40-47.
17. Sánchez E, Heredia N, García S (2005) Inhibition of growth and mycotoxin production of Aspergillus flavus and Aspergillus parasiticus by extracts of Agave species. Int J Food Microbiol 98: 271-279.

18. Krishnamurthy YL, Shashikala J (2006) Inhibition of aflatoxin B production of Aspergillus flavus, isolated from soybean seeds by certain natural plant products. Lett Appl Microbiol 43: 469-474.

19. Rosas-Taraco A, Sanchez E, Garcia S, Heredia N, Bhatnagar D (2011) Extracts of Agave americana inhibit aflatoxin production in Aspergillus parasiticus. World Mycotoxin J 4: 37-42.

20. Topçu G, Erenler R, Cakmak O, Johansson CB, Celik C, et al. (1999) Diterpenes from the berries of Juniperus excelsa. Phytochemistry 50: 1195-1199.

21. Barrero AF, Quílez del Moral JF, Lara A, Herrador MM (2005) Antimicrobial activity of sesquiterpenes from the essential oil of Juniperus thurifera. Planta Med 71: 67-71.

22. el-Sawi SA, Motawae HM, Ali AM (2007) Chemical composition, cytotoxic activity and antimicrobial activity of essential oils of leaves and berries of Juniperus phoenicea L. grown in Egypt. Afr J Tradit Complement Altern Med 4: 417-426.

23. Ortiz Y, Spengler I, Rodríguez Y, Collado IG, Hernandez-Galan R (2008) Screening Study of Potential Lead Compounds for Natural Products Based Fungicides from Juniperus lucayana. Natural Product Communications 3: 469-473.

24. Menghani K, Sharma SK (2012) Antimicrobial activity of Juniperus communis and Solanum xanthocarpum. International J Pharmacetical Sciences and Research 3: 2815-2818.

25. Tumen I, Fred JE, Carol AC, Jeffery AT (2013) Antifungal activity of heartwood extracts from three Juniperus species, BioResource 8: 12-20.

26. Samoylenko V, Dunbar DC, Gafur MA, Khan SI, Ross SA, et al. (2008) Antiparasitic, nematicidal and antifouling constituents from Juniperus berries. Phytother Res 22: 1570-1576.

27. Negash L (1995) Indigenous Trees of Ethiopia-Biology, Uses and propagation techniques. SLU Reprocentralen, Umea, Sweden, 285.

28. Pankaj k, Bhatt RP, Sati OP, Vinod KD, Lokendra S (2010) In-vitro antifungal activity of different fraction of Juniperus communis leaves and bark against Aspergillus niger and Aflatoxigenic Aspergillus flavus. International J Pharma and Bio Sci 1: 1-7.

29. Ortiz-Nunez Y, Spengler Salabarria I, Collado IG, Hernandez-Galan R (2010) Antifungal activity of extracts and terpene constituents of aerial parts of Juniperus lucayana. ev Latinoamer Quím 38: 145-152.

30. Pirzada AJ, Shaikh W, Kazi TG, Pervaiz I, Usmanghani K, et al. (2005) Isolation of essential elements and inhibition production of medicinal plant Datura alba seeds against human pathogenic fungi, Hamdard Med 48: 80-86.

31. Dutta TK, Das P (2001) Isolation of aflatoxigenic strains of Aspergillus and detection of aflatoxin B1 from feeds in India. Mycopathologia 151: 29-33.

32. Otto K, Mihaela T, Ovidiu T, Laura B, Florin B (2008) Reserches regarding aflatoxin production in feta chesse by direct contamination with Aspergillus flavus. Journal of Agroalimentary Processes and Technologies 14: 442-445.

33. Jan D, Robert AS (2007) Food Mycology A Multifaceted Approach to Fungi and Food, CRC Press 8, 137.

34. Pankaj k, Shailja D, Bhatt RP, Lokendra S (2011) In-vitro Antifungal activity of Sapium sebiferum L. against Aspergillus niger and Aflatoxigenic Aspergillus flavus. J Applied Pharmaceutical Sci 01: 108-110. 
35. Soković MD, Vukojević J, Marin PD, Brkić DD, Vajs V, et al. (2009) Chemical composition of essential oils of Thymus and Mentha species and their antifungal activities. Molecules 14: 238-249.

36. Pepeljnjak S, Kosalec I, Kalodera Z, BlazeviÄł N (2005) Antimicrobial activity of juniper berry essential oil (Juniperus communis L., Cupressaceae). Acta Pharm 55: 417-422.

37. Mariana F, Camelia U (2012) Antimicrobial activity of essential oils against four food-borne fungal strains. U.P.B. Sci Bull Series B 74: 87-98.

38. Glisic S, Svetomir M, Suzana ID, Aleksandar MO, Dejan US (2007) Antimicrobial activity of the essential oil and different fractions of Juniperus communis $\mathrm{L}$. and a comparison with some commercial antibiotics. J Serb Chem Soc 72: 311-320.

39. Migahid AM (1974) Flora of Saudi Arabia. Vol. 1, Cryptogams and dicotyledons equisetaceae to neuradaceae. 4th Edition; King Saud University Press, Riyadh, Saudi Arabia.

40. Chaudhary SA (1997) Flora of the Kingdom of Saudi Arabia, Vol. 1, National Agriculture and Water Research Centre. Ministry of Agriculture, Saudi Arabia, 691.

41. Domsch KH, Gams W, Anderson T (1980) Compendium of soil fungi. Acad. Press. (London). Ltd.

42. Domsch KH, Gams W (1972) Fungi in agricultural soils. Ongman, London. Ltd.

43. Raper KB, Fennell DI (1973) The Genus Aspergillus. Robert E Krieger Publishing Company, NewYork.

44. Frisvad JC, Filtenborg O, Thrane U (1989) Analysis and screening for mycotoxins and other secondary metabolites in fungal cultures by thinlayer chromatography and high-performance liquid chromatography. Arch Environ Contam Toxicol 18: 331-335.

45. Paterson RRM, Bridge PD (1994) Biochemical Techniques for Filamentous Fungi, CAB International, Wallingford, 125.

46. Thrane U (2001) Development in the taxonomy of Fusarium species based on secondary metabolites. In: Fusarium: Paul. E. Nelson, Memorial Symposium (Summerell, B.A., Leslie, J.F. Backhouse, D. Bryden,W.L. and Burgess, L.W. eds.). APS Press, St. Paul, MN, USA, 29-49.

47. Frisvad JC, Andersen B, Thrane U (2008) The use of secondary metabolite profiling in chemotaxonomy of filamentous fungi. Mycol Res 112: 231-240.

48. Vernon LP and Seely GR (1966) The chlorophylls. Academic Press, New York, London.

49. Mossa JS, Muhammad I, El-Feraly FS (1992) 3ß-Hydroxyabieta-8, 11,13tiene-1-one and other constituents from Juniperus excelsa leaves. Phytochemistry 31: 2789-2792.

50. Muhammad I, Mossa JS, El-Feraly FS (1996) Additional antibacterial diterpenes from the bark of Juniperus procera. Phytother Res 10: 604-607.

51. Kocić-Tanackov S, Dimić G, Lević J, Tanackov I, Tepić A, et al. (2012) Effects of onion (Allium cepa L.) and garlic (Allium sativum L.) essential oils on the Aspergillus versicolor growth and sterigmatocystin production. J Food Sci 77: M278-284.

52. Geraldo MRF, Arroteia CC, Kemmelmeier C (2010) The effects of neem [Azadirachta indica A. Juss (meliaceae)] oil on Fusarium oxysporum $f$. sp. medicagenis and Fusarium subglutinans and the production of fusaric acid toxin. Advances in Bioscience and Biotechnology 1: 1-6.

53. Bacon CW, Porter JK, Norred WP, Leslie JF (1996) Production of fusaric acid by Fusarium species. Appl Environ Microbiol 62: 4039-4043.

54. Kiran KG, Sri Rami RD, Yagnika NT, Annie SJ (2010) Exploitation of Aqueous Plant Extracts for Reduction of Fungal Growth and Detoxification of Aflatoxins. KMITL Sci Tech J 10: 52-62.

55. Grayer RJ, Harborne JB (1994) A survey of antifungal compounds from higher plants. Phytochemistry 37: $19-42$.

56. Al-Rahmah N, Mostafa A, Abdel-Megeed A (2011) Antifungal and antiaflatoxigenic activities of some plant extracts. African J Microbiol Res 5: $1342-1348$.

57. Feng W, Zheng X (2007) Essential oil to control Alternaria alternate in vitro and in vivo. Food Control 18: 1126-1130.

58. Imtiaj A, Rahman SA, Alam S, Parvin R, Farhana KM, et al. (2005) Effect of Fungicides and Plant Extracts on the Conidial Germination of Colletotrichum gloeosporioides Causing Mango Anthracnose. Mycobiology 33: 200-205.

59. Weitang S, Ligang Z, Chengzong Y, Xiaodong C, Liqun Z, et al. (2004) Tomato Fusarium wilt and its chemical control strategies in a hydroponic system. Crop Protect 23: 243-247.

60. Nguefack J, Torp J, Leth V, Lekane JB, Fotio D (2005) Effects of plant extracts and chemical fungicide in controlling a rice seed-borne fungus under laboratory and in irrigated cropping system in Ndop-Cameroon. African Crop Science Conference Proceedings 8: 791-796.

61. Bansal AK, Gupta RK (2000) Evaluation of plant extracts against Fusarium oxysporum, wilt pathogen of fenugreek. Indian Phytopathol 53: 107-108.

62. Abou-Jawdah Y, Wardan R, Sobh H, Salameh A (2004) Antifungal activities of extracts from selected Lebanese wild plants against plant pathogenic fungi. Phytopathol Mediterr 43: 377-386.

63. Ogbebor ON, Adekunle AT (2008) Inhibition of Drechslera heveae (Petch) M. B.Ellis, causal organism of Bird's eye spot disease of rubber (Hevea brasiliensis Muell Arg.) using plant extracts. African J General Agriculture 4: 19-26.

64. Shervin H, Kamran R, Salar J, Ali E (2011) Comparing Neem extract with chemical control on Fusarium oxysporum and Meloidogyne incognita complex of tomato. Advances in Environmental Biol 5: 2052-2057.

65. Lobna SN, Enas AMA (2012) Screening of antibacterial and antifungal activities of five medicinal plants from Saudi Arabia environment. J Applied Sciences Research 8: 2356-2365.

66. Hashem M, Moharam AM, Zaied AA, Saleh FEM (2010) Efficacy of essential oils in the control of cumin root rot disease caused by Fusarium spp. Crop Protection 29: 1111-1117.

67. John FL, Brett AS (2006) The Fusarium laboratory Manual, Blackwell Publishing Ltd.

68. Alkhail AA (2005) Antifungal activity of some extracts against some plant pathogenic fungi. Pak J Biol Sci 8: 413-417.

69. Mogle UP, Maske SR (2012) Efficacy of bioagents and fungicides on seed mycoflora, germination and vigour index of cowpea. Science Research Reporter 2: 321-326. 